\title{
BMJ Open Developments in the invasive diagnostic-therapeutic cascade of women and men with acute coronary syndromes from 2005 to 2011: a nationwide cohort study
}

\author{
Kim Wadt Hansen, ${ }^{1}$ R Soerensen, ${ }^{2}$ M Madsen, ${ }^{3} \mathrm{~J}$ K Madsen, ${ }^{4} \mathrm{~J}$ S Jensen, ${ }^{2,5}$ \\ L M von Kappelgaard, ${ }^{6,7}$ P E Mortensen,, ${ }^{7,8}$ S Galatius ${ }^{1,7}$
}

To cite: Hansen KW, Soerensen R, Madsen M, et al. Developments in the invasive diagnostictherapeutic cascade of women and men with acute coronary syndromes from 2005 to 2011: a nationwide cohort study. BMJ Open 2015:5:e007785.

doi:10.1136/bmjopen-2015007785

- Prepublication history and additional material is available. To view please visit the journal (http://dx.doi.org/ 10.1136/bmjopen-2015007785).

Received 26 January 2015 Revised 27 April 2015 Accepted 2 May 2015

CrossMark

For numbered affiliations see end of article.

Correspondence to Dr Kim Wadt Hansen; Kim.Wadt.Hansen@regionh.dk

\section{ABSTRACT}

Objectives: To investigate for trends in sex-related differences in the invasive diagnostic-therapeutic cascade in a population of patients with acute coronary syndromes (ACS).

Design: A nationwide cohort study.

Setting: Administrative and clinical registries covering all hospitalisations, invasive cardiac procedures and deaths in the Danish population of 5.6 million inhabitants.

Participants: We included 52565 patients aged 30-90 years who were hospitalised with a first ACS from January 2005 to November 2011. Follow-up was 60 days from the day of index admission.

Main outcome measures: Diagnostic coronary angiography, percutaneous coronary intervention or coronary artery bypass within 60 days of index admission.

Results: Women constituted $36 \%$, were older, had more comorbidity and were less likely to be admitted to a hospital with cardiac catheterisation facilities than men. Mortality rates were similar for both sexes. Diagnostic coronary angiography was performed less frequently on women compared with men, both within 1 day ( $31 \%$ vs $42 \% ; p<0.001)$ and within 60 days $(67 \%$ vs $80 \%$; $p<0.001$ ), yielding adjusted female-male HRs of 0.83 $(0.79-0.87)$ and $0.86(0.84-0.89)$, respectively.Among the 39677 patients undergoing coronary angiography, non-obstructive coronary artery disease was more frequent among women than men (22\% vs $9 \%$; $\mathrm{p}<0.001)$. Women were less likely to undergo percutaneous coronary intervention (58\% vs $72 \%$; $p<0.001)$ and coronary artery bypass $(6 \%$ vs $11 \%$, $\mathrm{p}<0.001$ ) within 60 days than men, yielding adjusted HRs of $0.96(0.92-0.99)$ and $0.81(0.74-0.89)$, respectively. The sex-related differences were not attenuated over time for any of the invasive cardiac procedures ( $p$ values for trend $>0.05$ ).

Conclusions: In this nationwide study, men were more likely to undergo an invasive approach than women when hospitalised with a first ACS - a difference persisting from 2005 to 2011. Future studies should focus on the potential mechanisms behind this differential treatment.

\section{Strengths and limitations of this study}

- Nationwide unselected cohort of 52565 patients with extensive information on demographics, out-hospital medication and comorbidities.

- Use of validated data from the Danish registries including detailed information on invasive cardiac procedures.

- Potential unmeasured confounding due to lack of core clinical data.

- Inability to discriminate between ST segment elevation and non-ST segment elevation myocardial infarction.

\section{INTRODUCTION}

Despite extensive historical knowledge of sexrelated differences in treatment and prognosis of patients with an acute presentation of ischaemic heart disease, ${ }^{1-3}$ contemporary empirical evidence supports that men are still more likely to receive diagnostic coronary angiography (DCA) and subsequent revascularisation than women, including recent results on large populations of patients with acute coronary syndrome (ACS). ${ }^{45}$ The underlying reasons for this disparity are poorly elucidated and difficult to investigate partly due to sex-related differences in clinical presentation, risk factors and comorbidity. ${ }^{6}$ Previous studies did not suggest any narrowing of sex-related differences in DCA or reperfusion therapy between 1999 and 2008. ${ }^{7-9}$ However, the context of these findings has changed in recent years. In Denmark, several steps have been taken to help ensure equal access for all cardiac patients to relevant healthcare services. First, in 2008-2009, the Danish National Health and Medicines Authority implemented national fast-track protocols for 
patients presenting with clinically stable non-ST segment elevation ACS (NSTE-ACS) aiming to reduce waiting times for DCA to $72 \mathrm{~h}$. Second, extensive prehospital field-triaging using ECG telemedicine has been gradually implemented in order to identify patients with ST segment elevation myocardial infarction (STEMI) in the ambulance enabling swift transportation to invasive heart centres. Finally, the Danish Heart Foundation ran a campaign focusing on public awareness of sex-related differences in presentation and treatment of cardiovascular diseases in 2007-2012. The campaign included advertisement on multiple media platforms using Danish female celebrities as leading figures. Also, a total of €2.14 million were allocated to 15 national research projects concerning women and cardiovascular disease. These national initiatives may have had a profound effect ideally offsetting any disparities in the invasive diagnostic-therapeutic cascade. Thus, we sought to investigate for trends in sex-related differences in the invasive diagnostic-therapeutic cascade using a contemporary population of patients with ACS.

\section{METHODS}

\section{Design and data collection}

We performed a nationwide register-based cohort study. All 5.6 million citizens of Denmark are covered by publicly financed national health insurance ensuring free access to healthcare services at all times. Each resident has a unique personal civil registration number enabling linkage of administrative healthcare data between nationwide registries. The Danish National Patient Registry holds information on all admissions to Danish hospitals since $1978 .{ }^{10}$ Each admission is registered by one primary diagnosis and, if appropriate, one or more secondary diagnoses in accordance with the International Classification of Diseases-before 1994 the 8th revision (ICD-8) and since 1994 the 10th revision (ICD-10). The primary diagnosis is assigned by the treating physician at discharge and describes the main reason for diagnostic investigation and treatment during a hospitalisation, while secondary diagnoses indicate additional comorbidity. The diagnosis of acute myocardial infarction (AMI) in the Danish National Patient Registry has been validated, showing sensitivity, specificity and a positive predictive value of $90-95 \% .^{11} 12$ The overall positive predictive value for ACS was $80 \%$. We collected data on invasive cardiac procedures from the Danish Heart Registry containing registration on all DCAs, percutaneous coronary interventions (PCI) and coronary artery bypass graftings (CABG) since the year $2000{ }^{13}$ These data have been validated previously. ${ }^{14}$ Information on preadmission medication consumption was obtained from the Danish National Prescription Registry holding data on all redeemed prescriptions according to the Anatomical Therapeutic Chemical classification. Owing to partial reimbursement of drug expenses by the Danish healthcare system, the pharmacies are required to register all disclosed prescriptions to ensure accurate registration. ${ }^{15}$ We obtained date and cause of death from the Danish Register of Causes of Death. ${ }^{16}$ Patient-level data on emigration, income, level of education, cohabitation status and distance to hospitals with cardiac catheterisation facilities were collected from Statistics Denmark who also performed all distance calculations using GIS (Geographical Information System) software. All unique identifiers were encrypted and data were kept and analysed on a secure server at Statistics Denmark.

\section{Study cohort}

We included all patients hospitalised with ACS (ICD-10 codes: I21 and I200) in Denmark from 1 January 2005 to 2 November 2011. Patients with a previous hospital admission for AMI (ICD-8 code 410; ICD-10 code I21) since 1978 or unstable angina pectoris (UAP; ICD-10 code I200) since 1995 were excluded to prevent potential misclassification due to an unknown predictive value of recurrent diagnoses of ACS. We excluded patients discharged on the day of admission to ensure that sufficient time to collect consecutive cardiac biomarkers and perform ECG monitoring necessary for establishing the diagnosis was available. Patients who died on the day of admission were also excluded as they were considered ineligible for an invasive approach. Finally, we restricted the cohort to include only patients aged 30-90 years. The aetiology of ACS in patients $<30$ years is heterogeneous and patients $>90$ years are often considered frail by physicians making them ineligible for DCA. ${ }^{17}$

\section{Setting}

The Danish national guidelines for treatment of patients with ACS follow the guidelines of the European Society of Cardiology. ${ }^{18}{ }^{19}$ Patients with ACS were referred to invasive heart centres from local hospitals or through well-developed emergency medical services depending on the clinical presentation. Only a minor group was self-directed or referred to emergency departments from their general practitioner. The number of patients undergoing intravenous thrombolysis is negligible in Denmark. A total of five invasive heart centres with facilities for performing DCA, PCI and CABG, and eight satellite centres with cardiac catheterisation facilities were operational during the study period.

\section{Outcome measures}

Invasive examination with DCA within 60 days of index admission was investigated for the entire study cohort. This observation period has been shown to capture the majority of DCA performed following ACS. ${ }^{4}$ Cardiac catheterisations performed within 1 and 3 days corresponding to early and delayed procedures were also assessed. Revascularisation with PCI or CABG within 60 days of index admission was investigated as composite and separate outcomes in the subgroup of patients who underwent DCA. 


\section{Explanatory variables}

\section{Demographic variables}

Each patient's age was categorised into 10-year intervals and included in the analyses as a categorical variable. Socioeconomic status was assessed by annual net family income after taxes calculated separately for patients $\leq 65$ and $>65$ years of age in order to account for any changes following retirement, highest achieved educational level and cohabitation status. ${ }^{20}{ }^{21}$ Annual net family income was divided into tertiles of low ( $\leq 65$ years: $<€ 34639 />65$ years: $<€ 27$ 132), medium (€34 639$€ 57633 / € 27$ 132-€44 512) or high (>€57 633/>€44 512) income. Highest achieved educational level was divided into three groups according to duration of training: short (a maximum of 9 years of school), medium (grammar school or vocational training) or long (university degree). The shortest distance needed to travel by road in order to reach a hospital with cardiac catheterisation facilities was calculated for each patient using range in kilometres from home address as of 1 January in the year of admission.

\section{Comorbidity}

Comorbidity was defined using primary and secondary diagnoses from up to 1 year prior to, until and including the index admission. Diagnoses of heart failure, cardiogenic shock, dysrhythmia and pulmonary oedema indicated the severity of heart disease. Diagnoses of malignancy, diabetes with complications, cerebrovascular disease, as well as acute and chronic renal failure were used to assess additional comorbidity. We used the ICD-10 coding in accordance with the work of So $e t a l,{ }^{22}$ who validated the ICD-10 codes based on the Ontario MI mortality predictive rule ${ }^{23}$ for the above comorbidities as predictors of death within 30 days and 1 year of AMI. Chronic obstructive pulmonary disease was included independently in the model (ICD-10; J40-44, $\mathrm{J} 47$ ) as a proxy for further chronic comorbidity. Prior revascularisation within 3 years of the index event was included in the analyses, as this may have influenced the decision to initiate invasive examination.

\section{Hospital transfers}

Transfer of patients between hospitals was identified using an algorithm that combined unique hospital identifiers, dates of admission and dates of discharge into one total index hospitalisation provided that dates were overlapping.

\section{Extent of coronary artery disease}

The extent of coronary artery disease was assessed by the number of vessels affected and categorised into four groups: no significant stenoses, one-vessel disease, two-vessel disease and three-vessel disease. The first group included findings of normal coronary arteries or diffuse non-obstructive atherosclerosis, while the latter two groups also included patients with left main coronary artery disease. A significant lesion was defined as at least $50 \%$ stenosis in a major epicardial vessel or CABG.

\section{Statistical analysis}

Continuous data are presented as median (IQR). Discrete data are presented as percentages. We used a nonparametric Mann-Whitney $\mathrm{U}$ test to test for differences in continuous variables. $\chi^{2}$ Test was used to compare discrete data and Fisher's exact test was used if the expected number of observations in a group was below 5 .

We calculated and plotted cumulative incidences for men and women using a competing risks model with allcause mortality as a competing risk. ${ }^{24}$ Sex-related differences in outcomes were estimated using univariable and multivariable proportional hazards Cox regression models applying robust estimation under the assumption that observations were correlated within individual hospitals. We applied a basic Cox regression model with sequential adjustments for age, year of admission, prior revascularisation, concomitant heart disease (cardiac arrhythmia, heart failure, pulmonary oedema and cardiogenic shock) and concomitant comorbidity (cancer, chronic obstructive pulmonary disease (COPD), cerebrovascular disease, diabetes with complications, acute renal failure and chronic renal failure). In the analyses on DCA, we performed additional adjustments for demographic characteristics including distance from place of residence to the nearest hospital with cardiac catheterisation facilities, income, level of education and cohabitation status. Similarly, we adjusted for extent of coronary artery disease in the analyses of revascularisation. Motivated by prior findings that severity of coronary artery disease as assessed during cardiac catheterisation may affect the use of reperfusion therapy differently in women and men, ${ }^{25}$ we conducted an interaction analysis between sex and extent of coronary disease. Missing data were excluded from the Cox regression models, but sensitivity analyses including missing data as a separate level were performed to assess the influence on our estimates (see online supplementary material). Temporal trends in sexrelated differences were estimated in the fully adjusted Cox regression models by including an interaction term between sex and year of admission in the model and using a log-likelihood ratio test to test for significance.

Model assumptions-interactions, non-informative censoring and proportional hazards-were found valid unless otherwise indicated. All hypothesis tests had a two-sided significance level of 0.05 . Analyses were performed using Stata Statistics/Data analysis, MP V.13.0 (StataCorp, Texas, USA).

\section{RESULTS}

In Denmark, a total of 59031 patients were admitted with a first ACS from 1 January 2005 to 2 November 2011. In total 1035 patients died on the day of admission, 1953 patients were $<30$ or $>90$ years of age and 3478 patients were discharged on the day of 
hospitalisation. Adjusted 60-day mortality was similar between women and men (see supplementary material).

\section{Baseline characteristics}

Table 1 lists the baseline characteristics of women and men as well as the entire study population. Women constituted $36 \%$ of the study population. On index admission, women were on average 8 years older and presented with more comorbidity-including cardiac arrhythmias, heart failure, COPD, neoplastic disorders, cerebrovascular disease and diabetes with complications - than did men. Accordingly, a larger proportion of women were receiving antihypertensive medication, statins, $\beta$-blockers, aspirin and loop-diuretics prior to admission compared with men. Men, however, had more concomitant chronic renal failure than women. Also, men more frequently had a history of prior revascularisation compared with women. Inspite of living slightly further from hospitals with cardiac catheterisation facilities, men were more likely to be admitted directly to such a hospital and hence to be transferred during index admission. Finally, a higher proportion of women lived alone and had a lower income and a shorter education than did men.

\section{Invasive examination}

During the entire study period, a lower proportion of women were investigated with DCA at 1 day $(31 \%$ vs $42 \% ; \mathrm{p}<0.001)$, at 3 days $(36 \%$ vs $49 \% ; \mathrm{p}<0.001)$ and at 60 days $(67 \%$ vs $80 \%$; $\mathrm{p}<0.001)$ compared with men (table 1). The higher cumulative incidence of examination with DCA in men compared with women (figure 1A) resulted in an unadjusted female-male HR of 0.71 (0.68-0.74) with similar results at days $0-1$, days 2-3 and the following 56 days (table 2). Sequential adjustment for explanatory variables attenuated the $\mathrm{HR}$ to 0.86 (0.84-0.89) at day 60 with similar results at days $0-1$, days 2-3 and the following 56 days (table 2), suggesting consistently lower rates of DCA in women compared with men. When stratifying for year of admission, an equal increase in the cumulative incidence over time for both genders with a relatively larger increase from 20082009 to 2010-2011 was demonstrated (figure 1B). Accordingly, there was no interaction between sex and year of admission suggesting persistent sex-related differences (figure 1B, table 2). As an additional analysis to assess the robustness of our results, we excluded all patients with a diagnosis of UAP $(n=8474)$ and obtained estimates almost identical to those described above (see online supplementary material).

\section{Extent of coronary artery disease}

Among the 39677 patients examined with DCA within 60 days, women were more likely than men to have no obstructive stenoses $(22 \%$ vs $9 \%$; p<0.001), while twovessel and three-vessel disease were more frequent among men (20\% vs $15 \%$; $<<0.001$ and $17 \%$ vs $13 \%$; $\mathrm{p}<0.001$, respectively; table 3 ).

\section{Revascularisation}

Among patients examined with DCA within 60 days of index hospitalisation, less women were revascularised compared with men $(63 \%$ vs $81 \%$; $<<0.001)$. This was consistent for the use of PCI $(58 \%$ vs $72 \%$; $<<0.001)$ and CABG $(6 \%$ vs $11 \%$; $<0.001)$, respectively (table 3$)$. The higher cumulative incidence for revascularisation when examined with DCA within 60 days in men compared with women (figure 2A) yielded an unadjusted HR of 0.66 (0.64-0.69). Adjusting for explanatory variables including the extent of coronary disease attenuated the HR to 0.93 (0.90-0.96). Stratifying for the year of admission demonstrated an equal slight increase in the cumulative incidence over time for both genders (figure 2B). Looking at PCI and CABG separately in the fully adjusted models, female gender was associated with a slightly lower rate of PCI at 60 days with HR 0.96 (0.93$0.99)$, on days $0-1$ with HR $0.96(0.93-0.99)$ and on days 2-60 with HR 0.94 (0.89-0.98). A similar estimate for CABG at day 60 was HR 0.81 (0.74-0.89). There were no interactions between sex and year of admission in either model, suggesting that sex-related differences remained (figure 2B, see online supplementary material).

A significant interaction between the extent of coronary artery disease and sex was present $(p<0.001)$, suggesting that the findings on coronary angiography modified the association between sex and revascularisation. More specifically, the sex-related differences were confined to patients with no significant stenosis or onevessel disease (figure 3) and those undergoing CABG (data not shown).

\section{DISCUSSION}

\section{Principal findings}

In this nationwide study of patients hospitalised with a first ACS in 2005-2011, we found no attenuation of sexrelated differences in the invasive diagnostic-therapeutic cascade. Women were $14 \%$ less likely than men to undergo DCA within 60 days, a difference that was present from the day of admission. Similar but less pronounced differences were found for subsequent revascularisation, but were limited to patients with no significant stenoses or one-vessel disease.

\section{Study strengths and weaknesses}

Our study population was comprised of a large unselected cohort of patients with ACS. Inclusion of all Danish citizens aged 30-90 years (constituting 3.2 million inhabitants in 2009) regardless of social status, attachment to the labour market or race minimises potential selection bias giving a nationwide perspective of the handling of patients with ACS.

Our study had several limitations that should be considered when interpreting the findings. The study was strictly observational. We were unable to directly measure the implementation and effect of the national public awareness campaign, fast-track protocols and 


\begin{tabular}{|c|c|c|c|c|}
\hline & $\begin{array}{l}\text { Women } \\
n=19056\end{array}$ & $\begin{array}{l}\text { Men } \\
n=33509\end{array}$ & p Value & $\begin{array}{l}\text { All } \\
N=52565\end{array}$ \\
\hline \multicolumn{5}{|l|}{ Demographics } \\
\hline Age at admission* & $73(62-81)$ & $65(56-75)$ & $<0.001$ & $68(58-78)$ \\
\hline Low income & $6916(36)$ & $10825(32)$ & $<0.001$ & $17741(34)$ \\
\hline Short education $\ddagger$ & $8842(46)$ & $10766(32)$ & $<0.001$ & $19608(37)$ \\
\hline Living alone§ & $10659(56)$ & $11093(33)$ & $<0.001$ & $21752(41)$ \\
\hline \multicolumn{5}{|l|}{ Distance in kilometres to nearest } \\
\hline Invasive heart centre* & $43(12-77)$ & $44(14-79)$ & $<0.001$ & $43(13-78)$ \\
\hline Hospital with cardiac catheterisation facilities* & $23(8-41)$ & $23(8-42)$ & $<0.001$ & $23(8-42)$ \\
\hline \multicolumn{5}{|l|}{ Risk factors } \\
\hline \multicolumn{5}{|l|}{ Medications prior to index admission (\%) } \\
\hline Antihypertensive medication & $10577(56)$ & $14949(45)$ & $<0.001$ & $25526(49)$ \\
\hline Statin or other lipid-lowering drug & 5077 (27) & $8347(25)$ & $<0.001$ & $13424(26)$ \\
\hline$\beta$-blockers & $5016(26)$ & $6593(20)$ & $<0.001$ & $11609(22)$ \\
\hline Aspirin & 6309 (33) & $9247(28)$ & $<0.001$ & $15556(30)$ \\
\hline Loop diuretics & 3671 (19) & $3676(11)$ & $<0.001$ & $7347(14)$ \\
\hline \multicolumn{5}{|l|}{ Concomitant heart disease (\%) } \\
\hline Cardiac arrhythmia & 2505 (13) & $3555(11)$ & $<0.001$ & $6060(12)$ \\
\hline Heart failure & $2055(11)$ & $2924(9)$ & $<0.001$ & $4979(9)$ \\
\hline Pulmonary oedema & $156(1)$ & $177(1)$ & $<0.001$ & $333(1)$ \\
\hline Cardiogenic shock & $103(1)$ & $164(1)$ & 0.44 & $267(1)$ \\
\hline \multicolumn{5}{|l|}{ Concomitant comorbidity (\%) } \\
\hline Cancer & $488(3)$ & $913(3)$ & 0.27 & $1401(3)$ \\
\hline COPD & $1531(8)$ & $1519(5)$ & $<0.001$ & $3050(6)$ \\
\hline Cerebrovascular disease & $1049(6)$ & $1398(4)$ & $<0.001$ & $2447(5)$ \\
\hline Diabetes with complications & $896(5)$ & $1433(4)$ & 0.02 & $2329(4)$ \\
\hline Acute renal failure & $172(1)$ & $358(1)$ & 0.07 & $530(1)$ \\
\hline Chronic renal failure & $275(1)$ & $621(2)$ & $<0.001$ & $896(2)$ \\
\hline \multicolumn{5}{|l|}{ Index hospitalisation } \\
\hline Length of hospital stay* & $5(3-8)$ & $5(3-7)$ & $<0.001$ & $5(3-7)$ \\
\hline Discharge diagnosis (\%) & & & $<0.001 \emptyset$ & \\
\hline Unstable angina pectoris & $3345(18)$ & $5129(15)$ & & $8474(16)$ \\
\hline Myocardial infarction & $15711(82)$ & $28380(85)$ & & $44091(84)$ \\
\hline Index admission at hospital with invasive cardiac facilities (\%) & $7398(39)$ & $14816(44)$ & $<0.001$ & $22214(42)$ \\
\hline Number of transfers (\%) & & & $<0.001 \emptyset$ & \\
\hline None & $12830(67)$ & $19745(59)$ & & $32575(62)$ \\
\hline 1 & $4345(23)$ & $9935(30)$ & & $14280(27)$ \\
\hline 2 or more & $1881(10)$ & $3829(11)$ & & $5710(11)$ \\
\hline \multicolumn{5}{|l|}{ Diagnostic coronary angiography (\%) } \\
\hline Day 1 & $5822(31)$ & $14125(42)$ & $<0.001$ & $19947(38)$ \\
\hline Day 3 & 6857 (36) & 16258 (49) & $<0.001$ & $23115(44)$ \\
\hline Day 60 & $12769(67)$ & 26919 (80) & $<0.001$ & $39688(76)$ \\
\hline \multicolumn{5}{|c|}{$\begin{array}{l}\text { *Median (IQR). } \\
\text { †Defined as a yearly income after all taxes below the first tertile in the study cohort (missing=245). } \\
\text { †Defined as a maximum of } 9 \text { years of school (missing=3670). } \\
\text { §Missing=164. } \\
\uparrow \chi^{2} p \text { Value for a } 2 x k \text { table. } \\
\text { COPD, chronic obstructive pulmonary disease. }\end{array}$} \\
\hline
\end{tabular}

prehospital triage. However, recent data suggest an impact of the latter two on access to invasive cardiac procedures in patients with ACS. ${ }^{26}{ }^{27}$ Because of the implementation of highly sensitive cardiac troponins and endorsement of the third universal definition of myocardial infarction, the composition of the ACS population in terms of STEMI, NSTEMI, and UAP may have changed during the study period. ${ }^{28}$ Information on core clinical variables, such as time of onset of symptoms, cardiac biomarkers, ECG findings or left ventricular ejection fraction, was not available to us; neither was information on prehospital data or out-hospital deaths. We were unable to discriminate between STEMI and NSTEMI, as the ICD-10 diagnoses for these subdiagnoses have not been validated in the Danish National Patient Register. Thus, we cannot rule out unmeasured 

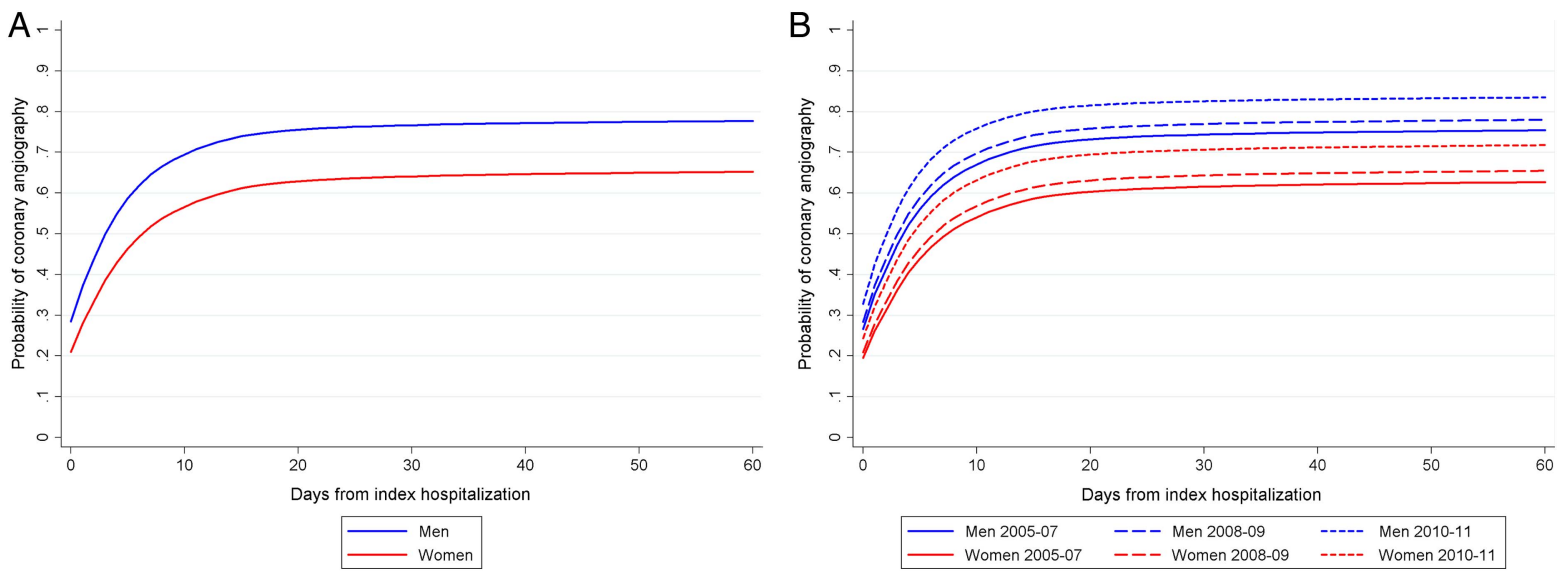

Figure 1 Cumulative incidence curves for undergoing coronary angiography within 60 days of admission with acute coronary syndromes.

confounding. Inclusion of clinical variables in future studies would allow for a validated severity score of ACS on presentation providing a tool to assess appropriateness of DCA use between sexes. Finally, our results only reflect Danish conditions in terms of geography and healthcare services.

\section{Interpretation}

In everyday clinical practice, referral of patients presenting with ACS to coronary angiography is preceded by a complex web of decision-making. Although these nuances are difficult to capture in administrative healthcare data, our observations have several interesting aspects. The sex-related differences in rates of DCA persisted throughout the study period with women being $15 \%$ less likely to undergo an invasive strategy. Similar results have previously been reported from other ACS registries. ${ }^{8} 9$ Even among more selected patients presenting with AMI and deemed ideal candidates for coronary angiography based on clinical presentation and availability of cardiac catheterisation on admission, women were consistently less invasively examined than men. ${ }^{7}$ This suggests that clinical variables alone cannot fully explain these disparities. Our analyses indicated that patient-related factors such as distance to nearest cardiac catheterisation hospital and socioeconomic status-factors that are correlated with access to healthcare and patient behaviour-did not account for the differential use of DCA according to sex. Although our findings do not bring us any closer to understanding the nature of these sex-related differences in referral for DCA, current evidence provides some clues. Unlike men, women presenting with low-risk NSTE-ACS do not seem to benefit from an early invasive approach. ${ }^{29}$ As physicians tend to underestimate patient risk in women, ${ }^{8}$ this may prevent or defer the use of coronary interventions. Also, women are more likely to experience periprocedural complications such as bleedings. ${ }^{30}$ Finally, it has been reported that sex-related differences in referral for cardiac catheterisation are only present in patients with equivocal indications for the procedure, ${ }^{31}$ suggesting either an overuse in men or an underuse in women.

In the subgroup of patients undergoing coronary angiography, non-obstructive coronary artery disease was found in $22 \%$ of women; more than twice as frequent as in men. This finding is consistent with the findings of prior studies $^{2932}$ and has been attributed to sex-related

Table 2 HRs for examination with coronary angiography in women versus men

\begin{tabular}{|c|c|c|c|c|c|c|}
\hline & Model 1* & Model $2 \dagger$ & Model 3‡ & Model $4 \S$ & Model 5П & $\begin{array}{l}\text { p Value for } \\
\text { interaction }^{\star \star}\end{array}$ \\
\hline DCA at 60 days & $0.71(0.68-0.74)$ & $0.84(0.82-0.86)$ & $0.83(0.81-0.85)$ & $0.84(0.82-0.87)$ & $0.86(0.84-0.89)$ & 0.34 \\
\hline Days 0-1 & $0.70(0.66-0.73)$ & $0.80(0.77-0.83)$ & $0.81(0.77-0.85)$ & $0.83(0.79-0.87)$ & $0.84(0.80-0.88)$ & 0.85 \\
\hline Days 2-3 & $0.73(0.70-0.76)$ & $0.86(0.82-0.90)$ & $0.85(0.81-0.89)$ & $0.86(0.81-0.90)$ & $0.87(0.83-0.91)$ & 0.67 \\
\hline Days 4-60 & $0.71(0.68-0.74)$ & $0.88(0.85-0.91)$ & $0.85(0.82-0.88)$ & $0.86(0.83-0.89)$ & $0.90(0.87-0.93)$ & 0.28 \\
\hline
\end{tabular}

${ }^{*}$ Model 1: unadjusted.

†Model 2: adjustment for age group.

¥Model 3: model 2+adjustment for year of admission, prior revascularisation, cardiac arrhythmias, heart failure, pulmonary oedema, cardiogenic shock, cancer, COPD, cerebrovascular disease, diabetes with complications, acute and chronic renal failure and distance to nearest hospital with cardiac catheterisation facilities.

$\S$ Model 4: model 3+adjustment for use of antihypertensive medication, statin or other lipid-lowering drug, $\beta$-blockers, aspirin, and loop-diuretics prior to index admission.

qModel 5: model 4+adjustment for income, level of education and living alone $(n=48609)$.

**Log-likelihood ratio test $p$ value for interaction between sex and year of admission using model 5 .

COPD, chronic obstructive pulmonary disease; DCA, diagnostic coronary angiography. 
Table 3 Result of coronary angiography and subsequent revascularisation

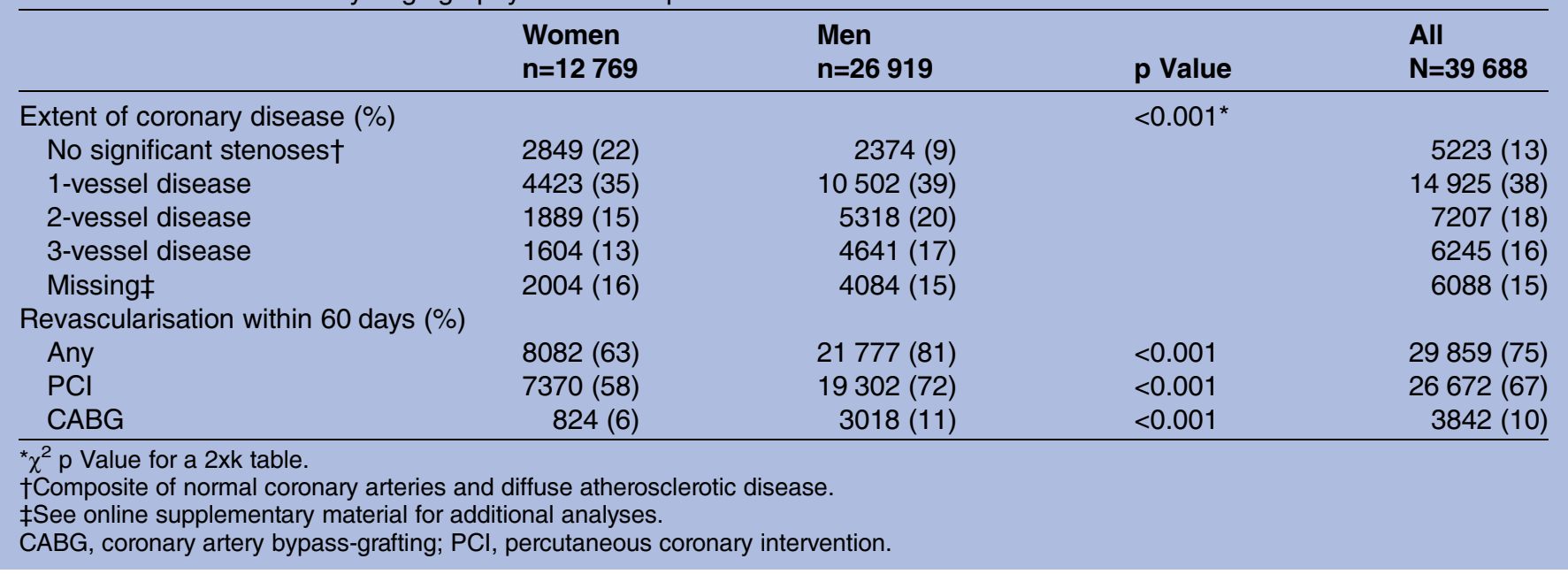
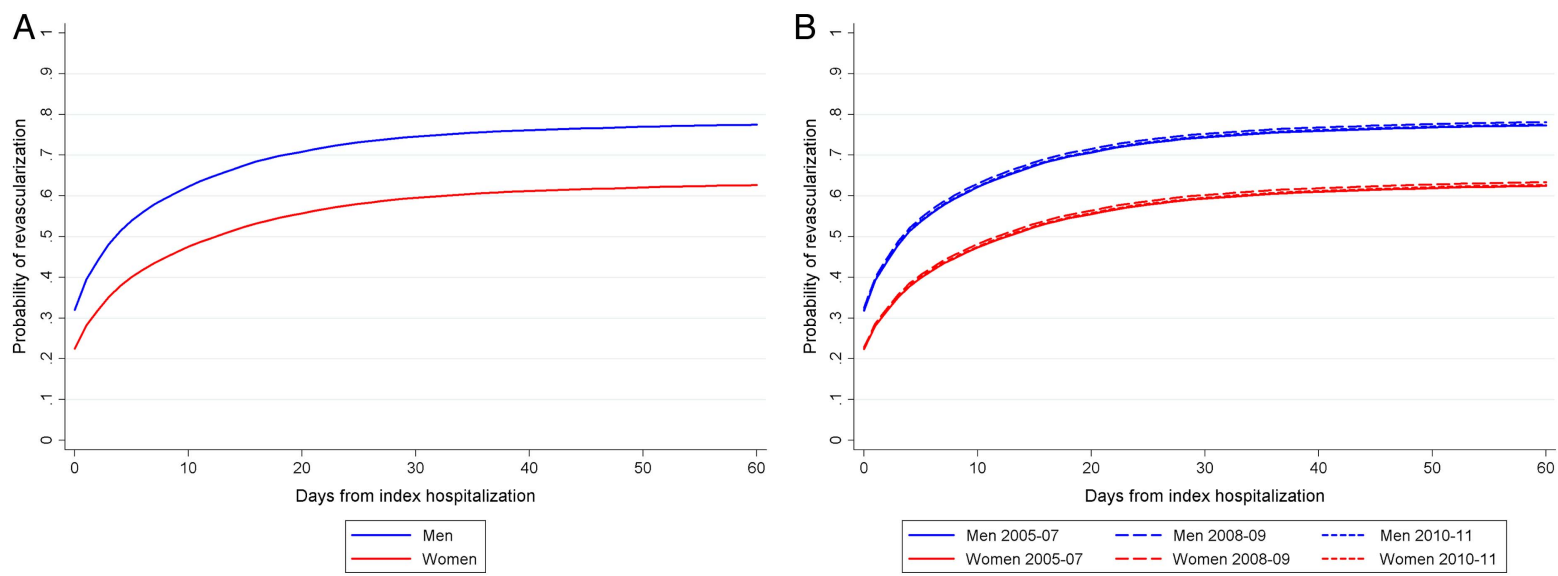

Figure 2 Cumulative incidence curves for undergoing any revascularisation within 60 days of admission among patients with acute coronary syndromes examined with coronary angiography.

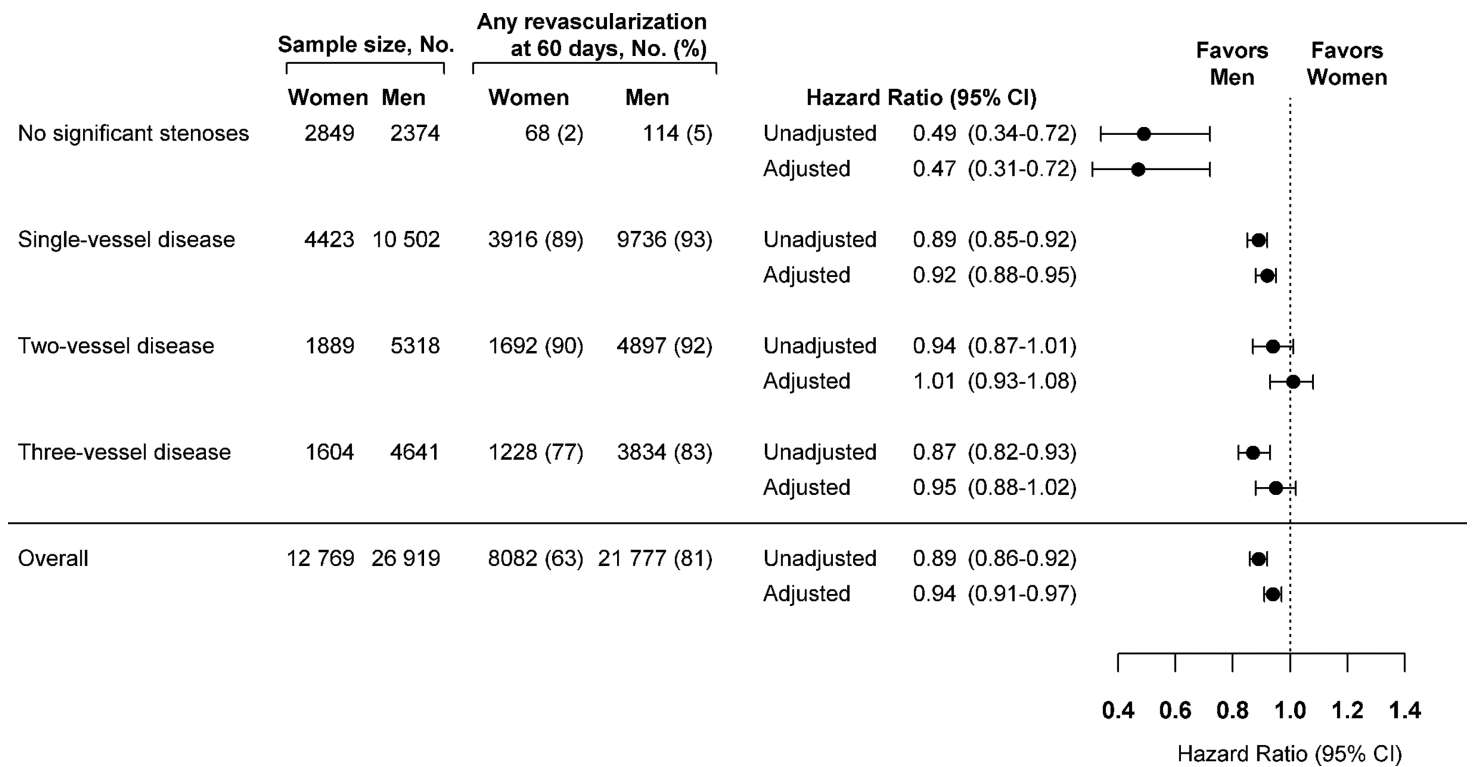

Figure 3 Unadjusted and multivariable-adjusted revascularisation at 60 days in women versus men stratified by extent of coronary artery disease. Adjusted model with adjustments for age group, year of admission, prior revascularisation, cardiac arrhythmias, heart failure, pulmonary oedema, cardiogenic shock, cancer, chronic obstructive pulmonary disease, cerebrovascular disease, diabetes with complications, acute and chronic renal failure. 
differences in the aetiology of MI with, for example, coronary artery spasms, rupture or erosion of eccentric plaques, microvascular disease including Takotsubo syndrome being more frequent in women. ${ }^{33} 34$ However, recent data also suggest that a sex-specific diagnostic threshold for MI using high-sensitivity troponins could reclassify women at an increased risk of reinfarction or death who would otherwise be missed using conventional cut-off values. ${ }^{35}$ Hence, the relatively high prevalence of unobstructed coronary arteries in women versus men undergoing DCA may reflect a differing underlying aetiology rather than an exaggerated incorrect use of the MI diagnosis in women.

Although women were less likely to be revascularised than men, these differences were largely explained by the extent of coronary artery disease in patients undergoing PCI. The remaining differences were driven by higher rates of revascularisation in men with nonobstructive or one-vessel disease as compared with women, even though rates of CABG remained higher in men. This is consistent with prior findings of higher rates of revascularisations in men when not clinically indicated compared with women. ${ }^{36}$ However, the lack of core clinical variables in our analyses prevents us from drawing any firm conclusions. Coronary angiography is usually performed with intention to revascularise, if possible. Therefore, procedure-related factors such as vessel size, tortuosity and potential complications would in all likelihood explain the remaining sex-related differences in selection for reperfusion therapy.

In conclusion, despite extensive national measures with a shared goal of ensuring equal access to invasive cardiac procedures, sex-related differences in the use of invasive examination and subsequent revascularisation were still present among patients admitted with a first ACS with no signs of a catch-up effect among women. Future studies of the clinical pathways precluding the decision to perform a cardiac catheterisation in women and men are needed to clarify the basis of the sex-related gap in invasive handling of patients with ACS. More specifically, the questions of whether a differing invasive approach in women and men represents a clinically appropriate strategy, an overuse of cardiac catheterisation in men or an actual underuse in women, and how this affects clinical outcomes need to be addressed adequately.

\footnotetext{
Author affiliations

${ }^{1}$ Department of Cardiology, University Hospital Bispebjerg, Bispebjerg, Denmark

${ }^{2}$ Department of Cardiology, University Hospital Gentofte, Hellerup, Denmark ${ }^{3}$ Department of Public Health, University of Copenhagen, Copenhagen, Denmark

${ }^{4}$ Emergency Department, Holbaek University Hospital, Holbaek, Denmark

${ }^{5}$ Institute of Clinical Medicine, University of Copenhagen, Copenhagen, Denmark

${ }^{6}$ National Institute of Public Health, University of Southern Denmark, Copenhagen, Denmark

${ }^{7}$ The Danish Heart Registry, Denmark

${ }^{8}$ Department of Thoracic Surgery, Odense University Hospital, Denmark
}

Acknowledgements The authors would like to thank the physicians providing data to the Danish Heart Registry for their hard work and continuous efforts.

Contributors KWH, RS, MM, JKM, JSJ, LMVK, PEM and SG participated in study design. KWH and SG obtained funding. KWH performed data analysis and wrote the report. All authors interpreted the results, revised the report and approved the final version.

Funding This work was supported by the Department of Cardiology at University Hospital Gentofte.

\section{Competing interests None declared}

Ethics approval The Danish National Health and Medicine Agency, the Danish Data Protection Agency and the Danish Heart Register approved the project, which was carried out in conformity with current rules of ethics and legislature. Register-based studies do not require ethical approval in Denmark.

Provenance and peer review Not commissioned; externally peer reviewed.

Data sharing statement No additional data are available.

Open Access This is an Open Access article distributed in accordance with the Creative Commons Attribution Non Commercial (CC BY-NC 4.0) license, which permits others to distribute, remix, adapt, build upon this work noncommercially, and license their derivative works on different terms, provided the original work is properly cited and the use is non-commercial. See: http:// creativecommons.org/licenses/by-nc/4.0/

\section{REFERENCES}

1. Steingart RM, Packer M, Hamm P, et al. Sex differences in the management of coronary artery disease. $N$ Engl $J$ Med 1991;325:226-30.

2. Ayanian JZ, Epstein AM. Differences in the use of procedures between women and men hospitalized for coronary heart disease. N Engl J Med 1991;325:221-5.

3. Clarke KW, Gray D, Keating NA, et al. Do women with acute myocardial infarction receive the same treatment as men? BMJ 1994;309:563-6.

4. Hvelplund A, Galatius S, Madsen M, et al. Women with acute coronary syndrome are less invasively examined and subsequently less treated than men. Eur Heart J 2010;31:684-90.

5. Fabreau GE, Leung AA, Southern DA, et al. Sex, socioeconomic status, access to cardiac catheterization, and outcomes for acute coronary syndromes in the context of universal healthcare coverage. Circ Cardiovasc Qual Outcomes 2014;7:540-9.

6. Shaw LJ, Bugiardini R, Bairey M. Women and ischemic heart disease-evolving knowledge. J Am Coll Cardiol 2009;54: 1561-75.

7. Vaccarino V, Rathore SS, Wenger NK, et al. Sex and racial differences in the management of acute myocardial infarction, 1994 through 2002. N Engl J Med 2005;353:671-82.

8. Poon S, Goodman SG, Yan RT, et al. Bridging the gender gap: insights from a contemporary analysis of sex-related differences in the treatment and outcomes of patients with acute coronary syndromes. Am Heart J 2012;163:66-73.

9. Nguyen HL, Goldberg RJ, Gore JM, et al. Age and sex differences, and changing trends, in the use of evidence-based therapies in acute coronary syndromes: perspectives from a multinational registry. Coron Artery Dis 2010;21:336-44.

10. Andersen TF, Madsen M, Jørgensen J, et al. The Danish National Hospital Register. A valuable source of data for modern health sciences. Dan Med Bull 1999;46:263-8.

11. Madsen M. The validity of the diagnosis of acute myocardial infarction in routine statistics: a comparison of mortality and hospital discharge data with the Danish MONICA registry. J Clin Epidemiol 2003;56:124-30.

12. Joensen AM, Jensen MK, Overvad K, et al. Predictive values of acute coronary syndrome discharge diagnoses differed in the Danish National Patient Registry. J Clin Epidemiol 2009;62:188-94.

13. Abildstrøm SZ, Kruse M, Madsen JK, et al. Dansk Hjerteregisteren klinisk database. Ugeskr Laeger 2008:170:532-6.

14. Abildstrøm SZ, Andersen S, Hvelplund A, et al. Dansk Hjerteregister -Årsberetning 2007. National Institute of Public Health 2007. http:// www.si-folkesundhed.dk/Links/Dansk\%20Hjerteregister/\%C3\% 85rsberetninger.aspx (accessed 16 Sep 2008).

15. Gaist D, Sørensen HT, Hallas J. The Danish prescription registries. Dan Med Bull 1997;44:445-8. 
16. Juel K, Helweg-Larsen $\mathrm{K}$. The Danish registers of causes of death. Dan Med Bull 1999;46:354-7.

17. Freisinger E, Fuerstenberg T, Malyar NM, et al. German nationwide data on current trends and management of acute myocardial infarction: discrepancies between trials and real-life. Eur Heart $J$ 2014;35:979-88.

18. Steg PG, James SK, Atar D, et al. ESC Guidelines for the management of acute myocardial infarction in patients presenting with ST-segment elevation: The Task Force on the management of ST-segment elevation acute myocardial infarction of the European Society of Cardiology (ESC). Eur Heart $J$ 2012;33:2569-619.

19. Hamm CW, Bassand J-P, Agewall S, et al. ESC Guidelines for the management of acute coronary syndromes in patients presenting without persistent ST-segment elevation: The Task Force for the management of acute coronary syndromes (ACS) in patients presenting without persistent ST-segment elevatio. Eur Heart $J$ 2011;32:2999-3054.

20. Rasmussen JN, Rasmussen S, Gislason GH, et al. Mortality after acute myocardial infarction according to income and education. J Epidemiol Community Health 2006;60:351-6.

21. Rasmussen JN, Rasmussen S, Gislason GH, et al. Persistent socio-economic differences in revascularization after acute myocardial infarction despite a universal health care system-a Danish study. Cardiovasc Drugs Ther 2007;21:449-57.

22. So L, Evans D, Quan H. ICD-10 coding algorithms for defining comorbidities of acute myocardial infarction. BMC Health Serv Res 2006;6:161.

23. Tu JV, Austin PC, Walld R, et al. Development and validation of the Ontario acute myocardial infarction mortality prediction rules. $J \mathrm{Am}$ Coll Cardiol 2001;37:992-7.

24. Gooley TA, Leisenring W, Crowley J, et al. Estimation of failure probabilities in the presence of competing risks: new representations of old estimators. Stat Med 1999;18:695-706.

25. Ghali WA, Faris PD, Galbraith PD, et al. Sex differences in access to coronary revascularization after cardiac catheterization: importance of detailed clinical data. Ann Intern Med 2002;136:723-32.
26. Quinn T, Johnsen S, Gale CP, et al. Effects of prehospital 12-lead ECG on processes of care and mortality in acute coronary syndrome: a linked cohort study from the Myocardial Ischaemia National Audit Project. Heart 2014;100:944-50.

27. Hansen KW, Sørensen R, Madsen M, et al. Nationwide trends in use and timeliness of diagnostic coronary angiography in acute coronary syndromes from 2005 to 2011: Does distance to invasive heart centres matter? Eur Hear J Acute Cardiovasc Care 2014 Published online first: 4 Dec 2014. doi:10.1177/2048872614562968

28. Thygesen K, Alpert JS, White HD. Universal definition of myocardial infarction. Eur Heart J 2007;28:2525-38.

29. O'Donoghue M, Boden WE, Braunwald E, et al. Early invasive vs conservative treatment in women and men with unstable angina and non-ST-segment elevation myocardial infarction-a meta-analysis. JAMA 2008;300:71-80.

30. Ahmed B, Dauerman HL. Women, bleeding, and coronary intervention. Circulation 2013;127:641-9.

31. Rathore SS, Wang Y, Radford MJ, et al. Sex differences in cardiac catheterization after acute myocardial infarction: the role of procedure appropriateness. Ann Intern Med 2002;137:487-93.

32. Shaw LJ, Shaw RE, Merz CNB, et al. Impact of ethnicity and gender differences on angiographic coronary artery disease prevalence and in-hospital mortality in the American College of Cardiology-National Cardiovascular Data Registry. Circulation 2008;117:1787-801.

33. Niccoli G, Scalone G, Crea F. Acute myocardial infarction with no obstructive coronary atherosclerosis: mechanisms and management. Eur Heart J 2014;36:475-81.

34. Reynolds HR, Srichai MB, lqbal SN, et al. Mechanisms of myocardial infarction in women without angiographically obstructive coronary artery disease. Circulation 2011;124:1414-25.

35. Shah ASV, Griffiths M, Lee KK, et al. High sensitivity cardiac troponin and the under-diagnosis of myocardial infarction in women: prospective cohort study. BMJ 2015;350:g7873.

36. Epstein AM, Weissman JS, Schneider EC, et al. Race and gender disparities in rates of cardiac revascularization: do they reflect appropriate use of procedures or problems in quality of care? Med Care 2003;41:1240-55. 